\title{
Modeling the Cost of Population Aging in Iran
}

\author{
Alireza Ghorbani ${ }^{1}$, Pouran Raeissi ${ }^{2} \&$ Mahnoosh Abdollah Milani ${ }^{3}$ \\ ${ }^{1}$ Department of Health Economics, School of Health Management and Information Sciences, Iran University of \\ Medical Sciences, Tehran, Iran \\ ${ }^{2}$ Department of Health Services Research, School of Health Management and Information Sciences, Iran \\ University of Medical Sciences, Tehran, Iran \\ ${ }^{3}$ Department of Economy, School of Economics, Allameh Tabatabaei University, Tehran, Iran \\ Correspondence: Pourani Raeissi, Department of Health Services Research, School of Health Management and \\ Medical Information Sciences, Rashid Yasemi St., Valiasr Av., above Vanak Sq., Tehran, Iran. Tel: \\ 98-912-301-0482. E-mail: raeissi2009@yahoo.com
}

\author{
Received: November 20, 2015 Accepted: March 3, 2016 Online Published: March 23, 2016 \\ doi:10.5539/gjhs.v8n11p140 \\ URL: http://dx.doi.org/10.5539/gjhs.v8n11p140
}

\begin{abstract}
Background and Objective: The decline in fertility rates and the increase in life expectancy have changed the demographic structure of many countries substantially and entail long-term economic implications too. Population aging has adverse effects on countries' economies, especially with respect to the social security system and the welfare structure.

Methods: Given the importance of the phenomenon of population aging and the increased longevity in recent decades, the present study was conducted to address the welfare implications of population aging in Iran during a span of 150 years using the Overlapping Generations (OLG) model.

Results: Examining the effect of reduced population growth or population aging on economic welfare, labor supply, capital assets and government expenditure during the span of 150 years suggested a decline in economic welfare in the early years; however, the rate of decline slowed down toward the end of the period; the same finding also applies to labor supply. Overall, population aging had the greatest impact on capital assets.

Conclusion: Population aging can cause a drastic transition in consumption and saving behaviors. Labor markets can also undergo similar transitions in their labor supply and have implications for labor productivity. The combination of these changes affects economic growth and welfare. The results of the study suggest that supporting the workforce and employing the immigrant population in the labor market can help reduce the adverse consequences of the phenomenon of population aging.
\end{abstract}

Keywords: Overlapping Generation Model, population aging, welfare

\section{Background}

The rising elderly population in both developed and developing countries is currently recognized as a factor that affects the social and economic structures of countries (G. Dausch, 2003). At the micro level, population aging leads to a greater vulnerability of individuals and households as well as the country's socioeconomic structure; at the macro level, it has adverse effects on the country's economy, particularly on the social security system and the welfare structure (Mierzaie \& Shams Ghahrokhi, 2007). What matters with respect to the demographic changes that take place in a country and their potential economic and financial implications is the government's response to the changes and the policies and plans that it adopts (Attarian, 2010).Reduced mortality rates, especially in the younger generation, and reduced fertility constitute a process known as demographic transition. Demographic transition has changed the age structure in many different countries and regions of the world through shifting the relative weight of the population from younger to older age groups. Age distribution is substantially less affected by international immigration than by fertility and mortality rates ("Development in an Aging World," 2007).

According to statistics, population aging has a direct reducing effect on labor supply and thereby the GDP. Over time, it also increases social security and welfare expenses incurred by the government, particularly pension and health expenses (Deger, 2008; Hviding \& Mérette, 1998; Pecchenino \& Pollard, 1997). 
Population aging has profound effects on a wide range of economic, political and social processes. For instance, concerns are growing about the survival of social security systems that are considered decisive for the welfare of both the younger and the older. The increased longevity implies that the government should pay benefits such as pension, health care or elderly support for longer periods, which necessitates changes in the social security systems in place (Sheikhi, 2010). Population aging is also associated with increased healthcare expenses; the model of increased healthcare expenses following aging is well-accepted. Population aging thus exerts an indirect pressure on public sector expenses (Keuschnigg, Davoine, Hofer, \& Schuster, 2012).

Demographers examine three main factors in relation to the phenomenon of population aging. First, the declining fertility rate in recent decades, which has diminished the relative number of younger individuals in favor of older individuals. The total fertility rate has dropped from 5 children per woman in 1950 to 2.5 in 2008 and is expected by the UN to further drop to 2 children per woman by 2050 ("World Population Aging 2009," 2009).This reduction is largely due to the changes in fertility rates in the developing world and is attributed to a number of factors, including reduced infant mortality, increased female education, increased work opportunities for women and the access to family planning services (Bloom, Canning, \& Fink, 2009). With the decline in fertility rates, mortality rates also decrease, particularly among the older individuals, thus exacerbating the phenomenon of population aging. In developed countries, especially in those with at least three decades of low fertility rates, improved old-age survival has increased older people's share of the total population ("The Power of 1.8 Billion Adolescents, Youth and the Transformation of the Future," 2014).

The second factor is the recent increase in longevity. The global life expectancy has increased from 47 years in 1950 to 65 in the present day and is expected to reach 75 by 2050. The increase in life expectancy is similar in developed and developing countries ("World Population Prospects: the 2012 Revision," 2013).

The third factor is age dynamics; that is, the changes occurred in death and birth rates. For instance, the post-WWII baby boom of wealthy countries has now reached a stage of population transition, and age groups born during the baby boom are now in a state of transition to the 60-year and higher age group (Weeks, 2008). Given the structural demographic, economic and social changes occurred over the last half century, life expectancy at birth and the ratio of the elderly population have increased in Iran and across the world and will continue to increase in the coming years, especially when those born in the 80 's become pensioners (Amini, Ingman, \& Sahaf, 2013).

Examining the indicators of population aging and their trends in the past few decades shows that the age structure of the country has changed and that the mean and median age are rapidly increasing among the population. The population of older individuals is predicted to increase by $200 \%$ in the next 15 years; in fact, the real extent of population aging will be perceivable after 2030, as the elderly population explosion is expected to occur only by then. Without a doubt, population aging imposes profound effects on the economic and social structure of societies and the pattern of resource distribution (Samadi, Dallal Esfahani, Sameti, \& Hafezi, 2012). The trend of population aging will witness a sharper increase in Iran than in other developing countries (Bagheri-Nesami \& Shorofi, 2014). To overcome the implications of this sharp increase, the government needs to adopt special policies and plans. The first step is then to determine the economic burden expected to be imposed by this phenomenon, particularly the burden on the social security and welfare systems. The present study was therefore conducted to assess the welfare implications of population aging in Iran. The researcher's review of literature revealed no studies on the economic implications of population aging in Iran, although other countries have examined this subject with respect to their own societies in several studies; in Iran, however, studies have mostly focused on political issues such as the retirement system and healthcare expenses rather than the issue of population aging. This study is different from previous studies in that it uses the OLG model and macroeconomic simulation analysis to examine and describe the economic changes associated with population aging.

\subsection{The Pension System in Iran}

The pension system in Iran is a defined benefit pension plan that incorporates insurance and a retirement plan. Currently, most pension funds in Iran are experiencing a rapid increase in their number of retired beneficiaries; the ratio of workers to retired people is therefore declining as a determinant of financial stability in defined benefit pension funds and pension funds are thus in a critical stage (World Bank, 2003). The pension system in Iran has two major funds that cover more than $90 \%$ of the workers and retired people in the public and private sectors. The Civil Servants Pension Fund is the oldest pension fund in Iran and covers only the public sector workers and is experiencing critical financial conditions due to the lower number of people entering the fund in the aftermath of reduced employments and the downsizing of the public sector. The Social Welfare Fund is the 
largest pension fund in Iran and covers both public and private sector workers. This fund has recently begun to cover all the new workers of the public sector and is therefore in a good and stable financial position. Other smaller funds cover workers in banking, the Military and the Ports and Maritime Organization (Sohofi Parast, 2008).

\section{Literature Review}

In one study conducted on the economic implications of population aging in Japan, Mackellar suggested that population aging may have a greater adverse effect on savings than on investment demands. A common aspect of the predictions about Japan's macro economy is therefore a reduced current account surplus to the point of financial deficit. The implications of population aging in Japan do not threaten only the national economy, but the global economy at large, and are predicted to have significant effects on financial markets and asset prices throughout the entire world (MacKellar, Ermolieva, Horlacher, \& Mayhew, 2013).

Ichiro Muto used the revised version of the OLG model and a set of data from 1982 to 2010 to also examine the economic implications of population aging in Japan and predicted them for the next three decades and showed that, due to the reduced ratio of the country's active population, population aging will have essentially opposite effects on GDP growth and GDP per capita (Muto, Oda, \& Sudo, 2012). Cagacan Deger studied the reforms in Turkey's social security system using the OLG model and concluded that these reforms will result in a short-term increase in fiscal deficit for the social security system; however, he concluded that the deficits would likely reduce in the medium or long-term (Deger, 2011).

Cristian Bulete used the OLG model to examine the effects of population aging on Romania'seconomy during a span of 100 years and proposed two scenarios based on social security budget adjustment. The first proposal was to adjust the participation rate to cover the increased financial needs, and the second was to accomplish a constant participation rate and to then adjust the age of retirement. In the first scenario, population aging had a significantly greater effect on the examined variables (Bulete, 2010).

Katerina Lisenkova studied the effect of population aging on economic growth in Ukraine over three stages of the country's demographic transformation and assessed its workforce structure and simulated a dynamic general equilibrium model for studying the relationships between the sectors in the proposed scenarios. She found that, in the best-case scenario, changes in the population's age structure continue to exert significant negative effects on the economy, particularly on the social security system and pensions (Lisenkova, 2009).

Sukpaiboonwat conducted a review study to examine the effect of population aging on economic growth and concluded that there are no frameworks for demonstrating the mechanism of population aging and whether this phenomenon has positive or negative effects on economic growth. He drew three conclusions from his study: (A) Population aging leads to a reduced economic growth; (B) Population aging imposes additional costs on the government; policies such as retirement plans and fertility schemes should therefore be modified; and (C) The rapid rate of population aging decreases the family's savings rate (Sukpaiboonwat, Plyngam, Jaroensathapornkul, 2014).

\section{Methods}

Population aging affects households' consumption behaviors, especially their consumption of goods and services associated with welfare and social security; in other words, the pattern of benefiting from the welfare and social security system changes over time under the influence of different factors (Auerbach \& Kotlikoff, 1987). Employment and economic activity determine how these benefits are used; population aging affects the labor market and disrupts the conditions; dealing with the resultant changes at the national level then requires the adoption of new government policies, especially fiscal policies (Cipriani, 2013). Choosing the right analytical model for determining the economic implications of the phenomenon of population aging is therefore essential. This model should simultaneously examine the behavior of all the constituent sectors of the economy and their interactions. The OLG model boasts these features and can be used to analyze the effects of population aging on the national economy (Ljungqvist \& Sargent, 2004). In this model, the economy consists of four sectors, including the households, the firms, the government and the social security system.

\subsection{Model}

Based on the objectives of the study as well as the economic structure of Iran, a dynamic OLG model was designed based on Auerbach and Kotlikoff's (1987) and Rasmussen and Rutherford's (2001) frameworks.

This model assumes that an economy is made up of inhomogeneous individuals. Each individual lives in a limited number of periods. In each period, the oldest generation dies and a new generation enters the economy, and individual consumers of different generations have an optimized behaviour in terms of savings and 
workforce supply. Overall, personal decisions determine the total capital and workforce supply in an economy.

\subsubsection{Aggregate Demand}

The demand side includes balance sheet accounts associated with capital revenue (R), labor revenue (L), government transfer to households $(\mathrm{T})$, private sector consumption $(\mathrm{C})$, private sector net savings (S), government's initial budget deficit (D), trade deficit (B), investment (I), and net tax on capital revenue $\left(\mathrm{T}_{\mathrm{r}}\right)$ and labor revenue $\left(\mathrm{T}_{1}\right)$.

Total revenue balance figures are:

$$
R+L+T=C+S
$$

Investment-saving balance

$$
S-D+B=I
$$

Government budget obligations

$$
T^{r} R+T^{l} L=G+T-D
$$

The return on capital (after tax deductions) covers the interest plus capital depreciation, while investment covers growth plus depreciation. With the full features of the aggregate demand side at hand, the link between these features and the optimization of household behavior can be examined.

\subsubsection{Household Demand}

Assuming that the initial endowment of a household consists of units of time, the household has:

$$
w_{g, t}=w(1+\gamma)^{g}
$$

In this equation, $w$ is a measure of income that remains constant throughout life and from which household payments to the state are deducted as pension savings, also called social tax $\left(\mathrm{T}_{\mathrm{s}}\right)$ and labor income tax $\left(\mathrm{T}_{\mathrm{L}}\right)$ :

$$
w=\dot{w}-T_{L}-T_{S}
$$

The first-order optimization conditions for household behavior in generation zero are:

$$
\begin{gathered}
\frac{\partial U\left(c_{t}, l_{t}\right)}{\partial c_{t}}=\lambda \bar{p}_{t} \\
\frac{\partial U\left(c_{t}, l_{t}\right)}{\partial l_{t}}=\eta_{t} \\
\eta_{t}-\lambda \bar{p}_{t} \pi_{t} \geq 0 \perp l_{t} \leq w \\
\sum_{t=0}^{N} \bar{p}_{t} c_{t}=\sum_{t=0}^{N} \bar{p}_{t}\left[\pi_{t}\left(w-l_{t}\right)+\zeta_{t}\right] \\
l_{t} \leq w
\end{gathered}
$$

Where $\lambda_{\text {and }} \eta_{t}$ are shadow prices for lifetime budget constraints and initial endowmentfor each year, and $\bar{p}_{t}=(1-\bar{r})^{-t}$ is the current general price index in the steady state.

To solve the problem of household behavior optimization, the aggregate of relevant variables at the household level in all generations in year zero should balance the total revenue. The following equations should therefore hold for labor (L) and consumption $(\mathrm{C})$ revenues:

$$
\begin{gathered}
L=\sum_{t=0}^{N} \frac{\pi_{t}\left(w-l_{t}\right)}{(1+\gamma)^{t}} \\
C=\sum_{t=0}^{N} \frac{c_{t}}{(1+\gamma)^{t}}
\end{gathered}
$$

For ensuring the compatibility of the model, the aggregate value of assets should equal the aggregate value of domestic assets plus the current value of their gains. In this case, the aggregate value of domestic assets is positive and equals the value of the accumulated capital. In addition, due to the effect of permanent trade imbalance on trade balance, the total volume of assets is affected by the government's budget deficit (D), which implies that households might have been indebted to the government at the outset, making the permanent deficit scenario possible:

$$
\bar{A}=\sum_{t=0}^{N} m_{t}=(1+\bar{r}) K+(B-D) \frac{1+\bar{r}}{\bar{r}-\gamma}
$$

In Equation (11), $m_{t}$ is the value of assets saved by one generation at a given time $(t)$, defined as follows: 


$$
m_{t}=a_{t}\left(\frac{1+\bar{r}}{1+\gamma}\right)^{t}
$$

Where $a_{t}$ is assets saved by generation zero at $t$.

\subsubsection{Production Sector}

The present study assumes the one-sector manufacturing model compatible with the constituents of aggregate demand. It further assumes that all markets are fully competitive, that the production technology used is based on the Constant Elasticity of Substitution and that foreign trade is assumed standard, meaning that domestic and foreign goods are deficient substitutes and that the price of foreign goods is given in the world market; this assumption is compatible with the assumption of a small open economy. Manufacturing is performed using the inputs of the workforce and capital services within the framework of CES production technology.

\subsubsection{Social Security System}

This model assumes the social security system to be public and for the government to oversee it. Households are thus assumed to pay the government an annual sum as pension savings, also known as social tax. In return, the government pays households a sum of money as pension. The total payment made by households in their working years is assumed to equal the government's annual payment to households in their retirement. In other words, the social security system is assumed to be self-funding and to be financed by households through savings made during their working years.

\subsection{Competitive Equilibrium}

This section deals with the conditions required for establishing a balance between servers (i.e. the households, the manufacturers, the government and the social security system). In fact, given the optimized behavior framed within the discussed equations, households seek to maximize their inter-temporal consumption utility, while businesses seek to maximize their own profits within the government's fiscal policies (of which the social security system is also part). The present study thus seeks to predict the economic welfare, labor supply, capital availability and government expenditure for seeks to predict economic welfare, labor supply, capital availability and government expenditure for the next 150 years. In the discussed equilibrium establishment, some parameters are taken to be exogenous, including the over-18 population growth rate (i.e. the overall fertility rate), conditional probability of survival and the chain of macroeconomic variables, consisting of GDP, national revenue, consumption tax rate, capital tax, depreciation rate, GDP growth rate, etc. The present study also takes the issue of optimization and the equilibrium routes in question to be dynamically convergent and assumes that, over time, the system will follow a convergent, balanced and reliable path in accordance with the government's fiscal policies.

\subsection{Concluding the Model and the Solution}

To create a logical basis for welfare analysis, government expenditure, such as transfers to households at the base level, is assumed to be constant. To assess the effects of a policy, the government budget balance is taken for each period or for an infinite horizon of time. When reviewing the government budget balance for each period, taxes in the period are also adjusted. First, the model was solved for a steady state of balance, so as to obtain some of the model parameters, such as the share of inputs in the production function. After solving the model for the steady state, it was solved for the population aging scenario in the form of a reduced population growth rate scenario and the model was solved for the target variables in GAMS.

\subsection{Data}

The data used for solving the model were partly extracted from Iran's Social Accounting Matrix (SAM) of 2011 and partly from the exogenous values used for solving the model in other studies (See Table 1). 
Table 1. The exogenous parameter values

\begin{tabular}{lll}
\hline Parameter & Value (\%) & Study \\
\hline Actual annual interest rate & $5 \%$ & Based on a Central Bank report \\
Annual discount rate & $5 \%$ & Based on aCentral Bank report \\
& & Karimzadeh et al. (Karimzade, \\
Inverse inter-temporal elasticity & $0.25 \%$ & Nasrollahi, Samadi, \& Dallali esfahani, \\
& & 2013) \\
Elasticity of substitution between consumption and rest & 0.8 & Auerbach \& Kotlikoff \\
Conversion elasticity between domestic consumption and exports & 4 & Researcher's assumption \\
Armington elasticity of imports & 4 & Researcher's assumption \\
\hline
\end{tabular}

\subsection{Scenario}

To achieve the objectives of the study, a scenario was made of the phenomenon of population aging assuming a population growth rate reduction from $1.5 \%$ to $1 \%$. The effects of this phenomenon on the country's economic welfare, labor supply, capital availability and government expenditure were then assessed for a span of 150 years.

\section{Results}

By assuming a steady state, this study examined the effects of the reduced population growth rate scenario on economic welfare, labor supply, capital availability and government expenditure during a 150-year period and at 5 -year intervals and each of values in graphs is a result of balance the whole economy in each 5-years period.

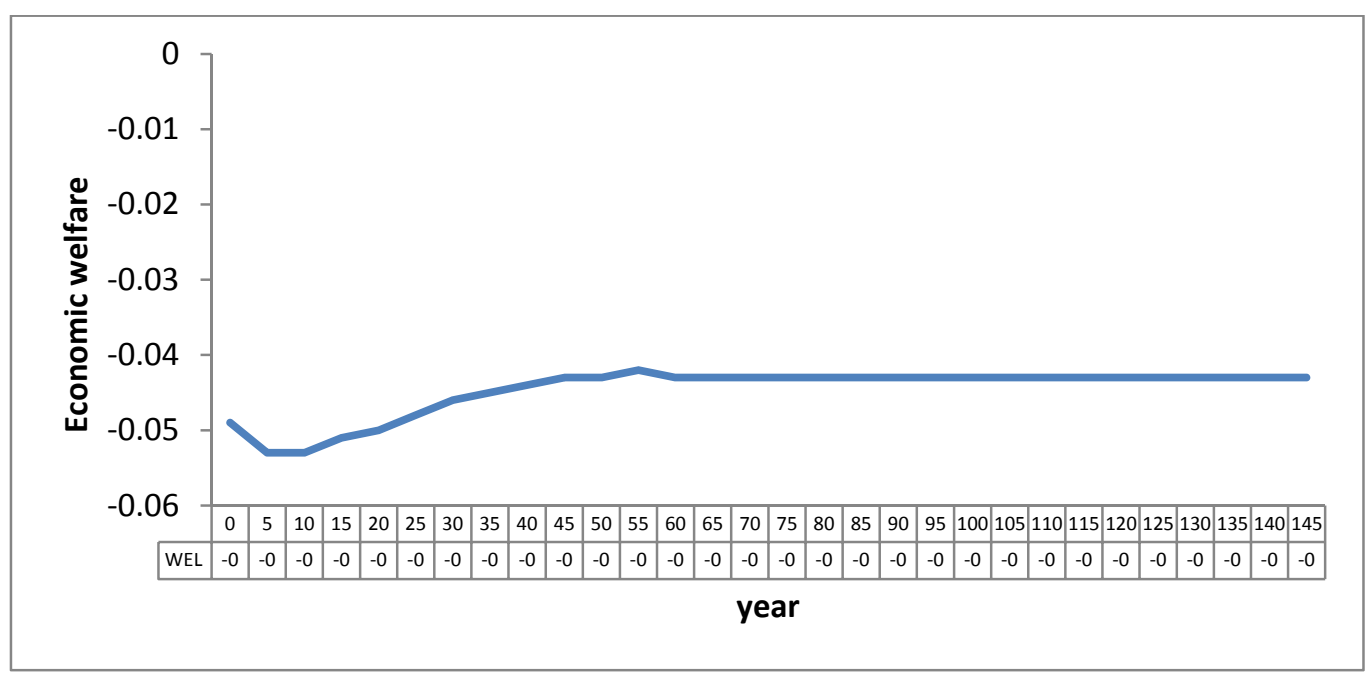

Figure 1. Changes in economic welfare caused by the population decline scenario

Source: Research findings

Figure 1 presents the effect of the reduced population growth rate scenario on economic welfare, showing a reduction of 0.049 in the level of socio-economic welfare during a steady state in year zero (2012). This scenario reduced economic welfare to -0.053 during the first 5 -year interval compared to during the steady state; however, no more reductions were witnessed during the second 5-year interval, during which economic welfare remained constant. Toward the third 5-year interval, the negative effect of population growth on economic welfare diminished and improvements were instead witnessed and economic welfare reached -0.051 . In the fourth 5-year interval, improvements in economic welfare persisted and reached -0.05 . The diminishing impact of population growth rate and improved economic welfare continued until the $11^{\text {th }} 5$-year interval, reaching -0.042 in the $55^{\text {th }}$ year. In the $12^{\text {th }} 5$-year interval, the impact of the population growth scenario grows lightly and economic welfare decreased insubstantially and returned to its $9^{\text {th }}$ and $10^{\text {th }}$ intervals' value $(-0.043)$. This trend then 
remained constant and showed no changes until the $30^{\text {th }} 5$-year interval, that is, until the end of the study.

Figure 2 presents the effect of the reduced population growth rate scenario on labor supply, showing an increase of 0.026 in labor supply during a steady state in year zero (2012). In the first 5-year interval, the reduction in population growth led to a significant reduction in labor supply compared to during the steady state, reaching -0.014. In the second 5-year interval, the labor supply showed an increasing trend; however, it remained negative $(-0.005)$ and showed a reduction compared to during the steady state. Labor supply began an increasing trend thereafter, reaching its maximum compared to during the steady state $(0.152)$ in the $11^{\text {th }} 5$-year interval. The declining trend of labor supply then began and continued until the $18^{\text {th }} 5$-year interval, when it reached 0.139 compared to during the steady state. Labor supply showed no tangible fluctuations until the end of the study caused by the reduced population growth and reached 0.141 in the last 5 -year interval.

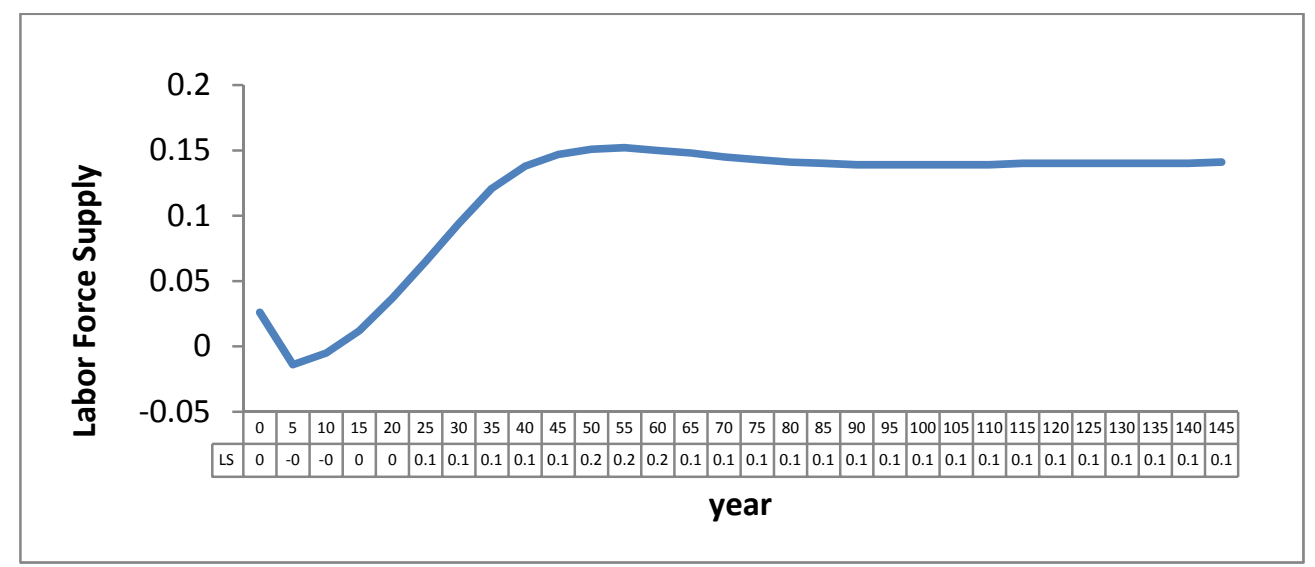

Figure 2. Changes in the workforce supply caused by the population decline scenario

Source: Research findings.

Figure 3 presents the effect of the reduced population growth rate scenario on capital availability after assuming a steady state, showing an increase of 0.008 in capital availability during a steady state in year zero (2012). Capital availability showed a declining trend in the second (-0.03) and third (-0.046) 5-year intervals compared to during the steady state, remaining constant through the third. In the fourth interval, capital availability began a gentle rising trend through to the 13th interval, when it reached a maximum of 0.067 compared to during the steady state. It should be noted that, capital availability remained negative compared to during the steady state until the fifth interval, but then increased gently with small fluctuations, reaching 0.062 in the last interval compared to during the steady state.

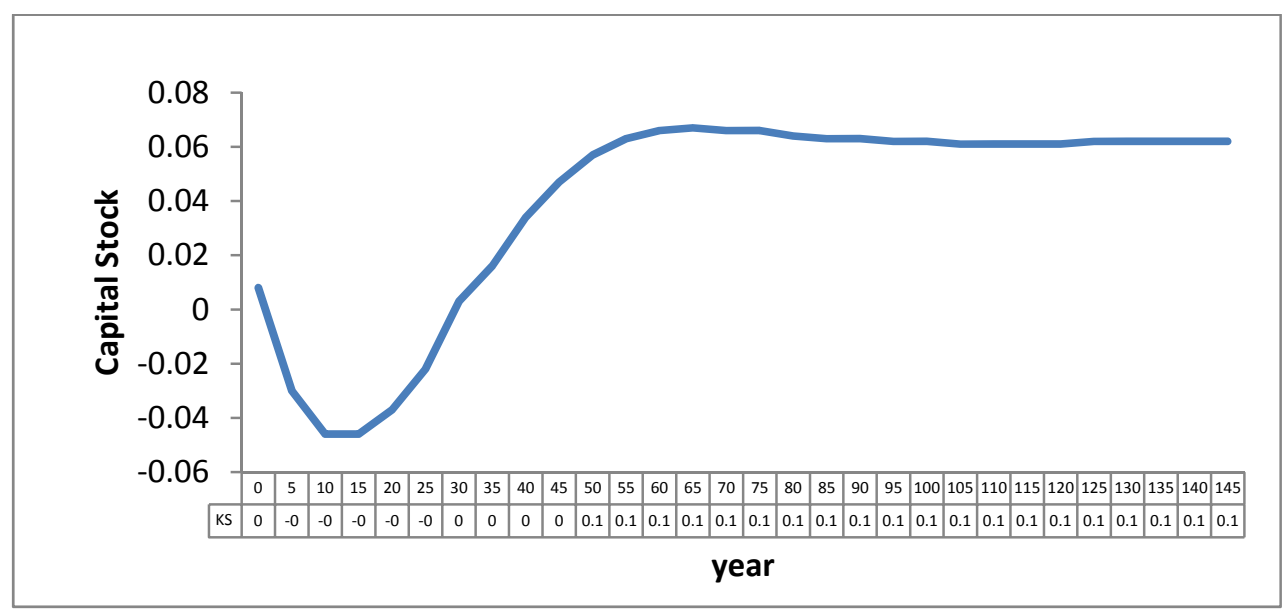

Figure 3. Changes in capital stock caused by the population decline scenario

Source: Research findings 
Figure 4 presents the effect of the reduced population growth rate scenario on government expenditure, showing a drop of -4.456 in government expenditure during a steady state in year zero (2012). Government expenditure showed a significant increase to -2.414 in the first 5 -year interval, and this increasing trend persisted through to the last interval, reaching a final value of -0.012 compared to during the steady state. It should be noted that, government expenditure remained negative compared to during the steady state throughout the study, approaching zero toward the end.

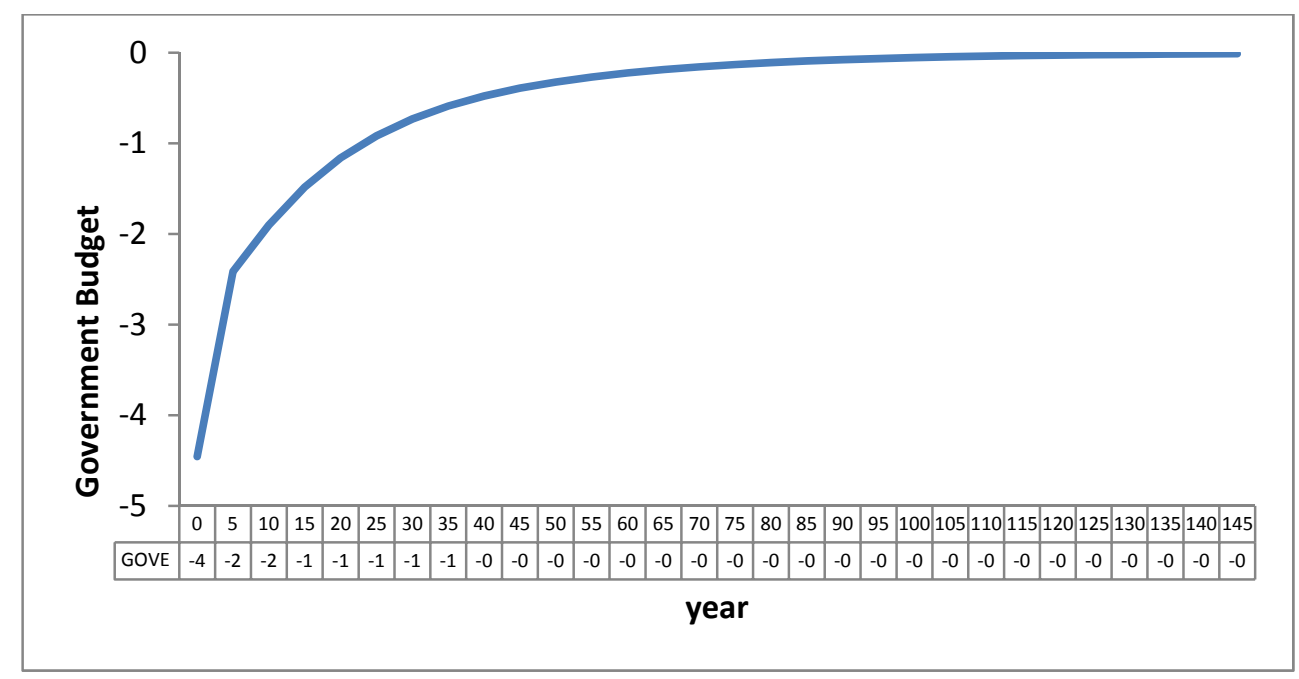

Figure 4. Changes in government budget caused by the population decline scenario

Source: Research findings.

\section{Discussion}

Population aging can have profound implications for the economy of a country and for societies experiencing a rapid increase in the ratio of the elderly to the total population. The scenario of reduced population growth and increased life expectancy increase the need for funding social security pensions. On the other hand, given the way pensions are funded as well as the reduced workforce, the ratio of workers to retired people covered by the fund lowers, creating constraints on the availability of new financial resources. The potential shortage of labor has negative effects on capital flows, thereby reducing investment in the manufacturing sector followed by a reduced GDP and a consequent reduction in the share of social security funds from the GDP. Reduced investments in the manufacturing sector further reduce employment opportunities and impose greater financial pressure on the social security system and problematize its funding in a vicious circle. Given the current national life expectancy, the death of a large number of retirees in the future and the subsequent reduction in the number of individuals covered by social security funds stabilize socio-economic welfare in the long-term. The reduced population growth and the subsequent reduced household size decrease children's education costs incurred by households in the long-term and increase households' consumption and savings, ultimately improving their welfare. With the reduced household size, cost-effectiveness and the fulfillment of needs increase and a relative improvement in welfare occurs.

With the reduced population growth rate, the labor supply witnesses an initial increase due to the large number of job candidates; nevertheless, with the constant reduction in the population growth rate, the ratio of older to younger people increases along with expenses. The employed and working-age population will then have to work longer hours, thereby increasing the labor supply. Pressured by the manufacturing sector and the increased costs, the workforce has to spend a major portion of its time working with little time left for rest, which then has a negative impact on welfare.

In the short-term, the population growth reduction scenario leads to a serious reduction in physical capital; one of the reasons for this reduction is that, due to the reduced population growth rate and labor shortages, replacing retired labor becomes impossible, and it will take ages to compensate for the lost capital. However, as the population growth rate and household size continue to decrease, household consumption expenses also decrease, resulting in an increase in the share of savings from the household income. These savings can then be invested in 
the manufacturing sector in the form of partnership with households and directly affect capital reserves. The reduced population growth rate then increases the ratio of older to younger people and directs the composition of production factors toward a gradual increase in the share of capital factors, leading to a significant increase in the capital to labor ratio through the process of production.

Population aging caused by a reduced population growth rate has significant effects on public and state expenditures, particularly on pension and health care funding, as these two expenses make up a major part of the government's budget. The pressures imposed by population change thus have negative effects on governments' budgets. In the reduced population growth rate scenario proposed in this study, government's budget remained negative compared to during the steady state, but approached zero in the long-term. The reduced population growth rate leads to an initial deficit due to the reduced production rate and government revenue. With the declining trend of the retired population caused by deaths and a limited life expectancy, general government spending then begins a declining trend too, and with the adjustment of expenses, budget deficits gradually decline.

\section{Conclusion}

According to the results obtained on the welfare implications of population aging in Iran, the reduction in population growth and the subsequent population aging can be said to reduce economic welfare in the short-term; in the long-term, however, the continued reduction in population growth increases economic welfare. Therefore researcher recommends based on the results obtained are that The health sector and pension funds to devise plans for dealing with the potential consequences of population aging (such as increased expenses). Also to use the immigrant workforce as a strategy for dealing with labor shortages caused by population aging and to also use the female workforce to compensate for the reduction in the number of working-age population.

With the emergence of the phenomenon of population aging, increasing the retirement age can encourage the greater participation of older people in social and economic activities. Literature reviews reveal demographic changes and an increasing elderly population in Iran. The ratio of elderly and dependent elderly to the total population is increasing. Countries can manage this phenomenon through adopting appropriate policies, facilitating action and creating suitable settings for minimizing elderlies' dependence.

\section{Ethical Issues}

This study was approved by the Ethics Committee of Iran University of Medical Sciences (Approved ethical code: 94/d/105/466).

\section{Acknowledgments}

This study was part of a $\mathrm{PhD}$ thesis supported by Iran University of Medical Sciences (Grant No: IUMS/SHMIS/2014/622).

\section{Authors' Contribution}

The first author had the key roles in designing the study, data collection and statistical analysis; the others contributed to writing the preliminary draft of the manuscript.

\section{Funding/Support}

This study has been funded and supported by School of Health Management and Information Sciences, Iran University of Medical Sciences (IUMS).

\section{Conflict of Interest}

The authors declare that there is no conflict of interests regarding the publication of this paper.

\section{References}

Amini, R., Ingman, S. R., \& Sahaf, R. (2013). Aging in Iran: Past, Present and Future. The Journal of Aging in Emerging Economies, 4(1), 17-34.

Attarian, I. (2010). Financing of retirement plans with increased longevity, retirement age, how to change? . Tehran: Ministry of Welfare and Social Security.

Auerbach, A. J., \& Kotlikoff, L. J. (1987). Dynamic Fiscal Policy. Cambridge: Cambridge University Press.

Bloom, D. E., Canning, D., \& Fink, G. (2009). The Graying of Global Population and Its Macroeconomic Consequences PGDA Working Paper: Department of Global Health and Population Harvard School of Public Health.

Bulete, C. (2010). Macroeconomic Effects of the Population Ageing Phenomenon. (PhD), Bucharest Academy of 
Economic Studies, Romania.

Bagheri-Nesami, M., \& Shorofi, S. A. (2014). Cultural and Socio-Economic Factors on Changes in Aging among Iranian Women. Global Journal of Health Science, 6(3), 145. http://dx.doi.org/10.5539/gjhs.v6n3p145

Cipriani, G. P. (2013). Population Ageing and PAYG Pensions in the OLG Model. Discussion Paper Series. Germany: Institute for the Study of Labor (IZA).

Deger, C. (2008). Pension Reform in an OLG Model with Multiple Social Security Systems. Ankara Turkey: Economic Research Center Middle East Technical University.

Deger, C. (2011). An Overlapping Generations Analysis of Social Security Reform in Turkey. (PhD), Middle East Technical University, Turkey.

Development in an Ageing World. (2007). World Economic and Social Survey (pp. 212). New York: Department of Economic and Social Aff airs.

G. Dausch, J. (2003). Aging issues moving mainstream. Journal of THE AMERICAN DIETETIC ASSOCIATION, 103(6), 683-684. http://dx.doi.org/10.1053/jada.2003.50155

Hviding, K., \& Mérette, M. (1998). Macroeconomic Effects of Pension Reforms in The Context of Ageing Populations: Overlapping Generations Model Simulations for Seven OECD Countries. OECD Economics Department Working Papers. Paris: OECD Publishing.

Karimzade, M., Nasrollahi, K., Samadi, S., \& Dallali Esfahani, R. (2013). Optimal path of consumption, investment and GDP: the use of extended Ramsey in Iranian economy. Research for Sustainable Development, 12(4).

Lisenkova, K. (2009). The Impact of Population Ageing on the Economic Development of Ukraine. (PhD), Heriot-Watt University, UK.

Ljungqvist, L., \& Sargent, T. J. (2004). Recursive Macroeconomic Theory (2nd ed.). United States of America: MIT Press.

MacKellar, L., Ermolieva, T., Horlacher, D., \& Mayhew, L. (2013). Economic Impacts of Population Aging in Japan. Austria: International Institute for Applied Systems Analysis.

Mierzaie, M., \& Shams Ghahrokhi, M. (2007). Demography of Elderly in Iran according of 1335-1385 census. Iranian Journal of Ageing, 2(3), 326-331.

Muto, I., Oda, T., \& Sudo, N. (2012). Macroeconomic Impact of Population Aging in Japan: A Perspective from an Overlapping Generations Model (pp. 49). Tokyo: Bank of Japan.

Pecchenino, R. A., \& Pollard, P. S. (1997). The Effects of Annuities, Bequests, and Aging in an Overlapping Generations Model of Endogenous Growth. USA: Federal Reserve Bank of St. Louis.

The Power of 1.8 Billion. Adolescents, Youth and the Transformation of the Future. (2014). USA: UNFPA.

Rasmussen, T. N., \& Rutherford, T. F. (2001). Modeling Overlapping Generations in a Complementarity Format. USA.

Sheikhi, M. T. (2010). Sociology of Aging. Tehran: Harir.

Weeks, J. R. (2008). Population: An Introduction to Concepts and Issues (10th ed.). USA: Thomson Wadsworth.

World Population Ageing 2009. (2009). New York: United Nations.

World Population Prospects The 2012 Revision. (2013). New York: Department of Economic and Social Affairs.

\section{Copyrights}

Copyright for this article is retained by the author(s), with first publication rights granted to the journal.

This is an open-access article distributed under the terms and conditions of the Creative Commons Attribution license (http://creativecommons.org/licenses/by/3.0/). 